\title{
Some insights into the impact fatigue damage behaviour in laminated composites
}

\author{
Y. Ouroua, K. Azouaoui, A. Mesbah, N. Ouali \& T. Boukharouba \\ Laboratoire de Mécanique Avancée, USTHB, Algeria
}

\begin{abstract}
An experimental method for impact fatigue of low energy was devised to provide some insights into the impact fatigue damage behaviour and characterize the response of laminated glass/polyester composites under conditions of increasing impact energy and increasing number of impacts. The impact frequency and subsequent projectile velocity of an impact fatigue apparatus specially designed and fabricated was varied to provide a spread of incident energies. The internal damage as a consequence of repeated impacts was investigated at five different levels of incident impact energy in the range of 3 - 7J, with the laminated specimens. The results indicated that the laminates suffered severe microstructural damage under impact fatigue, including cracking of the resin, delaminations, crushing and fracture of the glass fibres. Macroscopic failure mode can also be observed, such as; formation of spherical crater and propagating crack at the back face of plates, formed by the tensileshearing failure of fibre bundles at the weaving level. The delamination behaviour in the laminated specimens depended largely upon the level of incident energy. Well-defined impact fatigue $\left(E-N_{f}\right)$ behaviour, showing an endurance limit at above $10^{4}$ impact cycles, has been demonstrated.

Keywords: impact fatigue, endurance curve, glass/polyester, delamination area, low velocity, life duration, cumulative impact energy.
\end{abstract}

\section{Introduction}

Composite materials have a behaviour beyond elasticity marked by the presence of local microscopic phenomena which is called damage. The impact damage mechanisms remain still badly understood because of the various fracture 
processes which can appear simultaneously. This damage can involve serious degradations in the mechanical properties, particularly bending stiffness.

The comprehension of the composite damage phenomena is essential for the development and design of structural parts of composite subjected in service to repeated impacts. Few works were interested in impact fatigue on composite. During repetitive impacts, microscopic cracks appear in the matrix, fibres break, delaminations emerge in the interfaces, which make difficult the prediction of damaged composite behaviour. Considerable efforts were granted to understand the impact response of composites, however impact fatigue on composite materials requires a greater differentiation, since the effect of repeated impacts on composite damage is of a complexity even more increased. This reason among others, like the little number of machines producing cyclic impacts, makes that this field was invested little by researchers. The general assessment on various studies effectuated to date on impact fatigue, shows that no standard configuration of specimens nor of unified experimental device were adopted (Wyrick and Adams [1], Shin and Maekawa [2], Azouaoui et al. [3]).

Compressive and tensile residual strengths of carbon/epoxy composites subjected to repeated impacts were measured by Wyrick and Adams [1]. The authors showed that impact energy level and impact number are the principal factors which influence the degradation of residual strength. The stiffness variation of plastics reinforced by glass fibres, subjected to impact fatigue, has been studied by Rotem [4]. Mittelman [5] was interested in the identification and characterization of carbon/epoxy response under repeated impacts of low energy. Thus, the evolution of bending residual strength at various impact energies and variable impact numbers was studied. The reduction in residual strength of repeatedly impacted specimens was also noticed by Mouritz et al. [6]. These authors determined the bending and shearing post-impact properties, of laminated composites containing glass fibres and ester of vinyl resin.

In many studies, the influence of impact energy on impact fatigue lifetime was demonstrated. A theoretical impact fatigue lifetime analysis of PPS short fibre composites was carried out by Lhymn [7]. Ho et al. [8] showed that the impact energy affects significantly the impact fatigue lifetime, represented here by the failure impact number. Ray et al. [9] like Roy et al. [10] examined the fatigue strength properties of composites by the analysis of the fatigue curves E- $\mathrm{N}_{\mathrm{f}}$ (impact energy - failure impact number).

This work deals with the impact fatigue behaviour of glass/polyester composite laminates, showing a classical fatigue behaviour by the plot of endurance curves.

\section{Experimental procedures}

\subsection{Specimen}

The material of the study is a 8 layers of E-glass/polyester woven fabric composite, laminated by contact moulding process to the thickness of $3.5 \mathrm{~mm}$ and $1.8 \mathrm{~mm}$. The volume fraction of E-glass fibre is $70 \%$. Impact fatigue specimens 
are cut to the following dimensions $280 \times 180 \times 3.5 \mathrm{~mm}$ and $280 \times 180 \times 1.8 \mathrm{~mm}$ from two plates of $2 \mathrm{~m}^{2}$ area, and $3.5 \mathrm{~mm}$ and $1.8 \mathrm{~mm}$ thickness.

\subsection{Impact fatigue device}

The impact fatigue machine is constituted by a crank-connecting rod mechanism which allow to produce cyclic impacts (Figure 1), using an impactor with hemispheric head $(\phi 20 \mathrm{~mm}, 5.5 \mathrm{~kg})$. The repeated impacts are obtained by transforming rotational motion into a translatory one by the crank-connecting rod mechanism. Two edges of specimens are embedded and five impact energies are selected $3 \mathrm{~J}, 4 \mathrm{~J}, 5 \mathrm{~J}, 6 \mathrm{~J}$ and $7 \mathrm{~J}$.

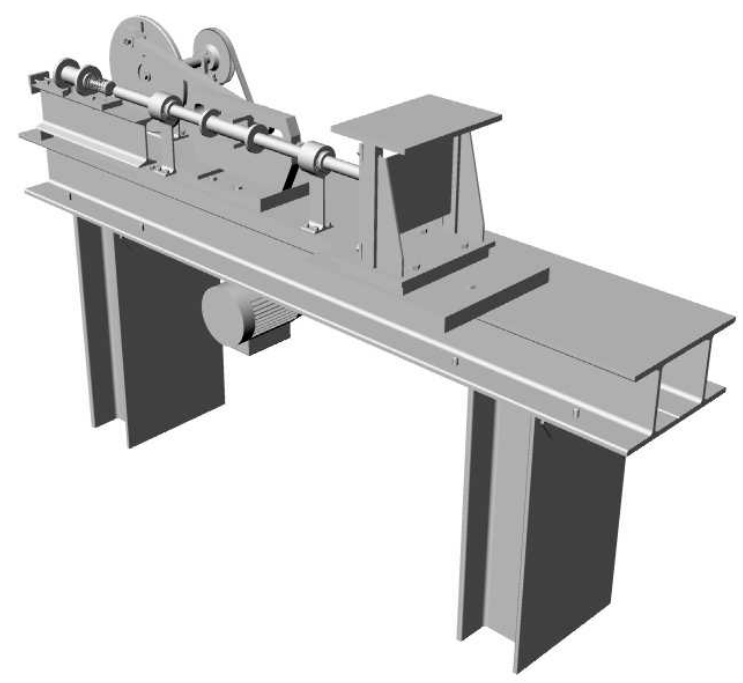

Figure 1: $\quad$ Impact fatigue machine.

The impact velocity is measured by using two parallel metallic blades located at a distance of $16 \mathrm{~mm}$ the one from the other, assembled on the impact fatigue machine frame, at a few millimetres of the impact point (in order to have a local measurement, right before the impact). An electrical contact between the impactor and these two metallic blades, is ensured at each cycle by an electric wire fixed on the impactor. The interception by an oscilloscope of the two signals due to the electric contact wire - metallic blades, allows to measure the flight time between the two metallic blades (at the time of the passage of the impactor) and then to deduce the projectile velocity.

The impact number is determined by a cycle counter. It is a piece of equipment constituted by a photoelectric cell with proximity detection and of a digital counter giving the impact number at each cycle. 


\section{Experimental results and discussion}

\subsection{Evolution of delamination area with impact fatigue tests}

In order to quantify delaminated surface and its evolution according to the number of impacts, we considered it useful to plot the curves of variations of this surface for various impact numbers, and this until total failure of the composite plate (Figure 2).

Figure 2 shows that between 1 and 1000 impacts, the variation of the delamination surface growths gradually and in a quasi-linear way, whose slope is much more marked when the energy level is higher. The impact number is one of the principal factors ally to the impact energy which influences considerably the damage and the failure of composite materials subject to impact fatigue.

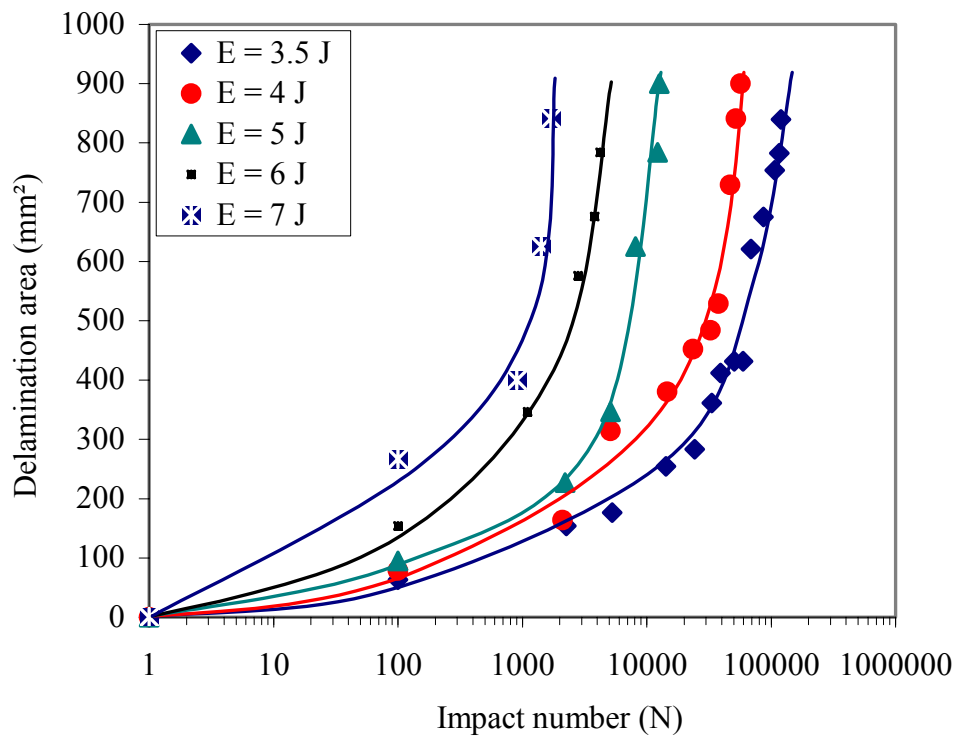

Figure 2: $\quad$ Evolution of delamination surface according to impact number.

The projected area of delamination developed with increasing cumulative impact energy is shown in Figure 3. The cumulative impact energy added to the specimen is determined from multiplying impact number by the incident impact energy. In both specimens, although there exist some differences depending upon the energy level, the projected area of delamination increased rapidly at first with an increase of the cumulative impact energy.

The curves reveals two distinct behaviours: for low impact energy $(3.5 \mathrm{~J}, 4 \mathrm{~J})$ the propagation of delamination presents three zones; a rapid increase at first, followed by a slower growth of delamination area, followed by an acceleration of damage until the total failure of specimen. This evolution in three phases can be explained by the fact that a great part of cumulative impact energy is absorbed 
in delamination in phases I and III, while the deceleration noted in the intermediate phase II indicates that the energy absorbed in delamination is less significant. That seems to be due to the fact that the other types of damage (mainly; punching of impact surface, crater growth, matrix cracking at opposite face, etc.) as well as the bending elastic strain of the plate, absorbs the part of energy lost by delamination during the second phase (Figure 3). For higher impact energies $(5 \mathrm{~J}, 6 \mathrm{~J}$ and $7 \mathrm{~J})$, the propagation of delamination growth rapidly in spite of the low impact number (Figure 3).

We can conclude that the impact number is the major damage factor for low energy levels $(3.5 \mathrm{~J}$ and $4 \mathrm{~J})$. But, as soon as the impact energy takes greater values $(\geq 5 \mathrm{~J})$, this one becomes the dominating factor. Let us note that after plate perforation, delamination areas reach values ranging between $784 \mathrm{~mm}^{2}$ and $900 \mathrm{~mm}^{2}$ and at any time these surfaces exceed a value higher than $900 \mathrm{~mm}^{2}$ for all the tested specimen with different energy levels.

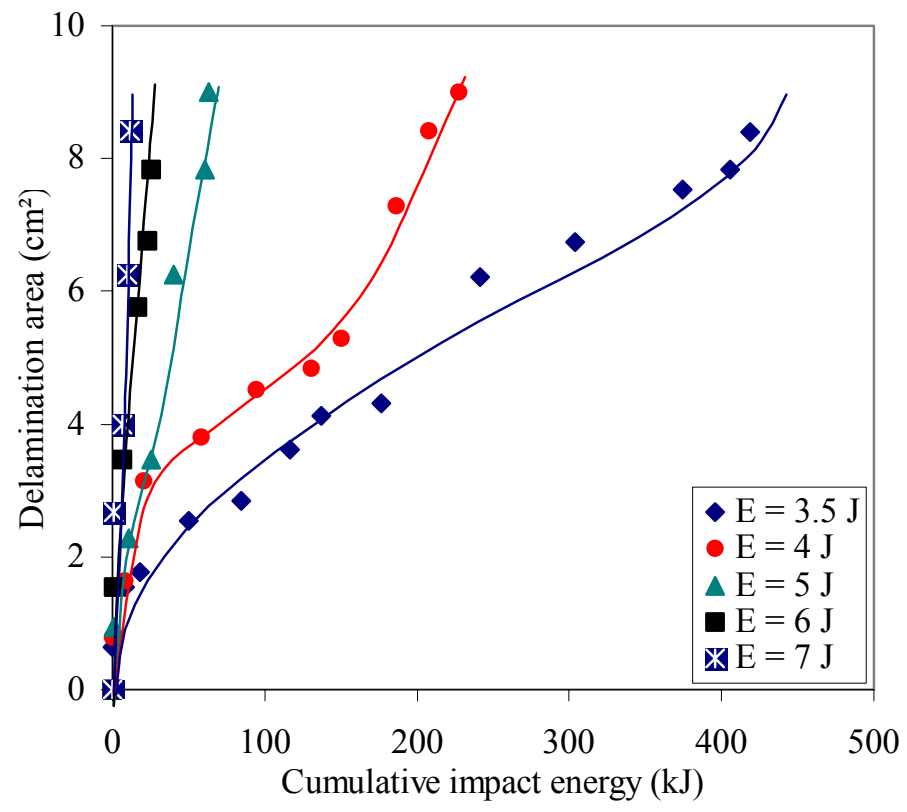

Figure 3: Evolution of delamination area according to cumulative impact energy.

\subsection{Endurance curves}

One of the principal objectives of this study is the plot of fatigue curves. That consists to carrying out the impact fatigue tests until the total failure of the composite plates. One notes then, for each energy level, the failure impact 
number or lifespan. The fatigue curves are obtained while carrying in $\mathrm{x}$-coordinates; the failure impact number and in ordinates; the energy level.

The lifespan is measured by the cycle number to failure $\mathrm{N}_{\mathrm{f}}$. The application of $\mathrm{N}$ cycles $\left(\mathrm{N}<\mathrm{N}_{\mathrm{f}}\right)$ involves a certain damage in the material which is significant to quantify because it determines its capacity of residual lifetime and thus can indicate if it is or not necessary to replace the defective part to avoid any accident.

Each specimen was perforated after a certain number of impacts and under a well defined energy. The results obtained were represented in the form of a curve characterizing the rupture of the material (perforation) according to energy level and impact number thus to each specimen corresponds a point of the plan $\left(E, N_{f}\right)$ (Figure 4).

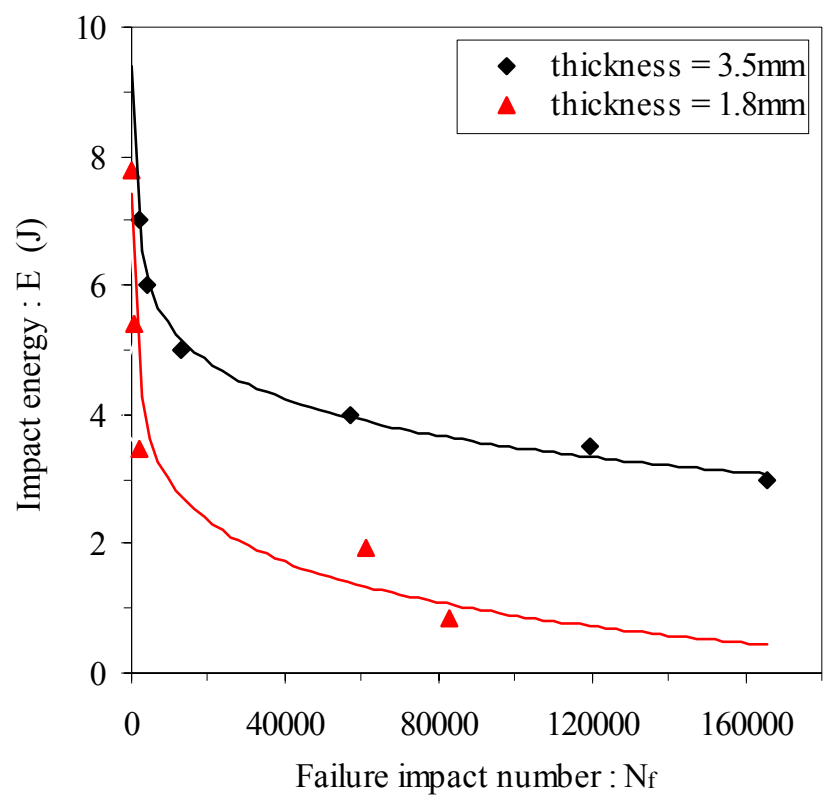

Figure 4: Fatigue curves for two different thickness $(3.5 \mathrm{~mm}, 1.8 \mathrm{~mm})$.

One can generally distinguish on this curve three distinct phases: for an energy level higher than $6 \mathrm{~J}$ (specimen thickness of $3.5 \mathrm{~mm}$ ) and higher than $4 \mathrm{~J}$ (specimen thickness of $1.8 \mathrm{~mm}$ ), the level of damage is very fast and the duration of repeated impacts until the perforation of the specimens is very short. The higher is the energy level, the more the perforation is imminent; case of oligocyclic fatigue.

For a range of energy ranging between 6 and 4J (specimen thickness of $3.5 \mathrm{~mm}$ ) and between 1.5 and $4 \mathrm{~J}$ (specimen thickness of $1.8 \mathrm{~mm}$ ) the degree of damage go less quickly than previously, in an interval of repeated impacts located between 5000 and 60000 impacts. The more the energy level decreases, 
the more the propagation of the damage slows down; case of fatigue of limited endurance.

For an energy level lower than $4 \mathrm{~J}$ (specimen thickness of $3.5 \mathrm{~mm}$ ) and lower than $1.5 \mathrm{~J}$ (specimen thickness of $1.8 \mathrm{~mm}$ ) the fatigue curve (Figure 4 ) shows that the parameters characterizing the damage of the plates will progress in a very slow way until the rupture. Indeed, this phase is located in an interval ranging between 60000 and 170000 impacts, described by the slope of a line of directing coefficient tending towards 0 when the impact number is very high; case of fatigue of unlimited endurance which one calls also zone of safety. This result enables us to conclude that below a certain value of threshold impact energy, the impacted material will never reach the rupture, result established by Lhymn [7].

The curve represented by Figure 5 can be compared to the endurance diagram or the Wöhler curve.

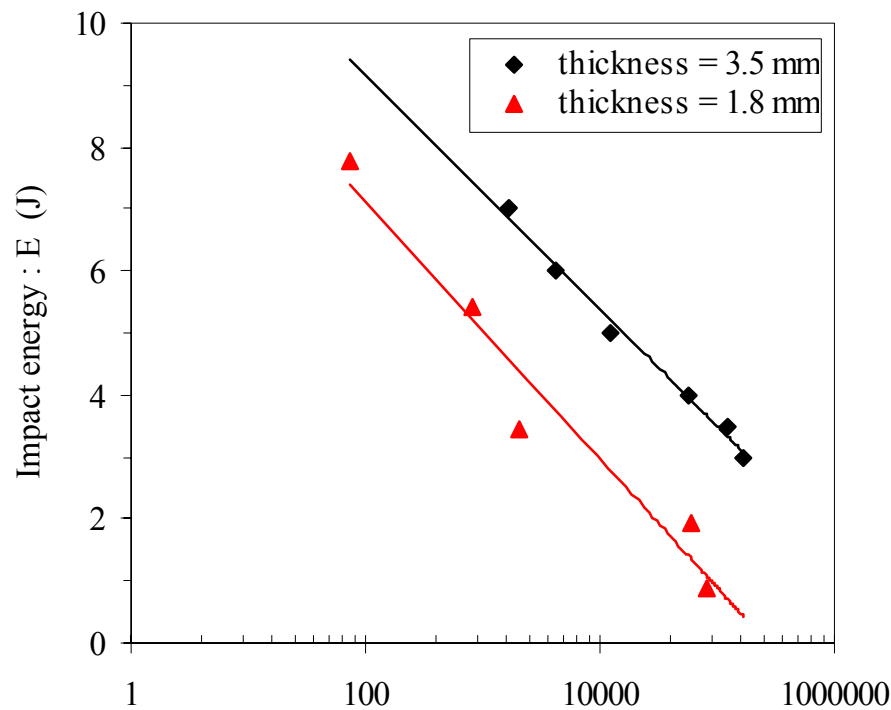

Failure iimpact number : $\mathrm{N}_{\mathrm{f}}$

Figure 5: $\quad$ Fatigue curve (logarithmic scale).

The effect of impact energy on failure impact number is shown in Figures 4 and 5 , it indicates that the failure impact number varies inversely with impact energy. This result represented by the curves of Figures 4 and 5 is extremely interesting, since one can a priori apply what is known on classical fatigue to the case of impact fatigue, by taking into account the specificities of this particular type of test.

The two curves seem to follow a power function (see eqns (1), (2) and (3)), as it is the case of Whöler curves. 
374 Structures Under Shock and Impact IX

$$
E=A \cdot N_{f}^{b}
$$

where the material constants $\mathrm{A}$ and $\mathrm{b}$ can be determined by the plot of the curve : $\log (\mathrm{E})=\log \left(\mathrm{N}_{\mathrm{f}}\right)$, which designate a straight line of slope $: \mathrm{b}$ and the intersection with y-coordinate is equal to $\log (\mathrm{A})$.

The lifetime relationship for specimen of $3.5 \mathrm{~mm}$ thickness is given by :

$$
E=25.57 \cdot N_{f}^{-0.173}
$$

The lifetime relationship for specimen of $1.8 \mathrm{~mm}$ thickness is given by:

$$
E=28.82 \cdot N_{f}^{-0.276}
$$

It is judicious to plot the curve of cumulative impact energy according to the failure impact number (Figure 6), in order to study the combined effect of impact number and energy level on the lifespan $\mathrm{N}_{\mathrm{f}}$.

Figure 6 shows that for high energy levels a weak cumulative impact energy is sufficient to break material corresponding to a lower impact number. The smaller is impact energy, and the more the composite plates tend never to break, in spite of the great energy cumulated by material. This zone of unlimited endurance is represented by the asymptote at the end of the curve.

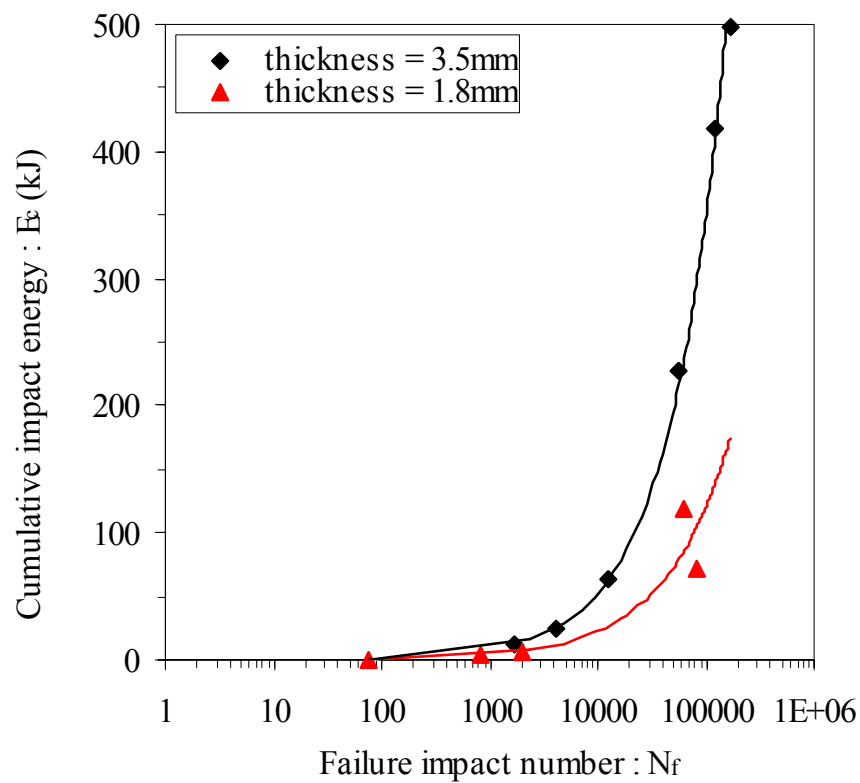

Figure 6: Evolution of cumulative impact energy with failure impact number. 


\section{Conclusion}

The principal results of this study are as follows:-

The impact number is the major damage factor for low energy levels $(3.5 \mathrm{~J}$ and $4 \mathrm{~J})$. But, as soon as the impact energy takes greater values $(\geq 5 \mathrm{~J})$, this one becomes the dominating factor. Indeed, delamination area growths considerably for high values of impact number when the energy level is low. For higher impact energies $(5 \mathrm{~J}, 6 \mathrm{~J}$ and $7 \mathrm{~J})$, the propagation of delamination growth rapidly in spite of the low impact number.

In our study a classical fatigue behaviour was demonstrated. Indeed, the plot of fatigue curve; impact energy according to failure impact number (representing the lifespan) emphasized a curve similar to the Wöhler curves, following a power law.

\section{References}

[1] Wyrick, D.A. \& Adams, D.F., Residual Strength of a Carbon/Epoxy Composite Material Subjected to Repeated Impact. J. Composite Materials, 22, pp. 749-765, 1988.

[2] Shin, H.S. \& Maekawa, I., Damage behaviors in CFRP laminates due to repeated impacts of low energy. Damage and failure of interfaces, ed. Rossmanith, (C) Balkema: Rotterdam, pp. 343-350, 1997.

[3] Azouaoui, K., Rechak, S., Azari, Z., Benmedakhene, S., Laksimi, A. \& Pluvinage, G., Modelling of damage and failure of glass/epoxy composite plates subject to impact fatigue. International J. Fatigue, 23, pp. 877-885, 2001.

[4] Rotem, A., The strength of laminated composite materials under repeated impact loading. J. Composite Science and technology. Res., pp. 74-79, 1988.

[5] Mittelman, A., Low-energy repetitive impact in carbon-epoxy composites. J. Materials Science, 27, pp. 2458-2462, 1992.

[6] Mouritz, A.P., Gallagher, J. \& Goodwin, A.A., Flexural Strength and Interlaminar Shear Strength of Stitched GRP Laminates Following Repeated Impacts. Composites Science and Technology, 57, pp. 509-522, 1997.

[7] Lhymn, C., Impact fatigue of PPS/glass composite - part I Theoretical analysis. J. Materials Science Letters, 4, pp. 1221-1224, 1985.

[8] Ho, K.C., Hwang, J.R. \& Doong, J.L., Impact Fatigue of Short Glass Fiber Reinforced Polycarbonate. J. Reinforced Plastics and Composites, 16(10), pp. 903-925, 1997.

[9] Ray, D., Sarkar, B.K. \& Bose, N.R., Impact fatigue behaviour of vinylester resin matrix composites reinforced with alkali treated jute fibres. Composites Part A : applied Science and manufacturing, 33, pp. 233-241, 2002. 
376 Structures Under Shock and Impact IX

[10] Roy, R., Sarkar, B.K. \& Bose, N.R., Impact fatigue of glass fibrevinylester resin composites. Composites Part A : applied Science and manufacturing, 32, pp. 871-876, 2001. 